\title{
Investigações das ações pedagógicas dos professores de educação física: método tradicional $x$ aprendizagem significativa
}

Ações pedagógicas pautadas em métodos que caracterizem práticas do ensino tradicional não proporciona aos estudantes uma educação capaz de prepará-los para as exigências do atual modelo de sociedade, desta forma, o modelo da aprendizagem significativa proposto por David Ausubel é uma importante proposta metodológica para os professores de Educação Física. A Educação Física escolar busca no contexto atual de sua utilização, através da cultura corporal do movimento, formar seres com hábitos saudáveis, críticos e transformadores. Sendo assim o objetivo geral deste artigo é identificar as ações pedagógicas de ensino dos professores de Educação Física. Para este estudo foi utilizado um questionário contendo 26 afirmações. Este questionário foi elaborado com embasamento na escala likert, que é uma escala psicométrica muito utilizada em pesquisas de cunho qualitativo. Este estudo se caracteriza como uma pesquisa descritiva. Este estudo utilizou como amostra 6 professores da disciplina de Educação Física da cidade de Mauriti-Ce. Para a análise das respostas alcançadas foi empregada uma pontuação nas ações dos professores. Neste modelo de pontuação, os resultados que tenham média superior a 3 mostram ações que possibilitam e se aproximam da Aprendizagem Significativa. Já as médias abaixo de 3 evidenciam a utilização de métodos voltados para a metodologia do Ensino Tradicional. A média geral das assertivas, segundo os dados obtidos pelas respostas, mostra que os professores realizam em sala, práticas que possibilitam uma aprendizagem significativa. A média geral de 5 professores investigados foi superior a 3 , atingindo média superior a 4, nas assertivas referente as ações pedagógicas que caracterizam metodologias voltadas para a aprendizagem significativa. Pode-se observar que os professores sabem da importância em oferecer aos estudantes, meios e ferramentas que proporcione uma aprendizagem significativa, em que os novos conteúdos devem estar atrelados e conectados ao conhecimento do aluno sobre a temática proposta, para que possa aprender. Ainda é importante ressaltar que os professores precisam rever certos costumes pedagógicos tradicionais que não favorecem a uma boa qualidade de ensino, e de fato agir e não somente falar.

Palavras-chave: Educação Física; Ensino Tradicional; Aprendizagem Significativa.

\section{Investigations of pedagogical actions of physical education teachers: traditional method $x$ meaningful learning}

\begin{abstract}
Pedagogical actions based on methods that characterize traditional teaching practices do not provide students with an education capable of preparing them for the requirements of the current model of society, thus, the model of significant learning proposed by David Ausubel is an important methodological proposal for students. Physical Education teachers. School Physical Education seeks in the current context of its use, through the body culture of the movement, to form beings with healthy, critical and transforming habits. Thus, the general objective of this article is to identify the pedagogical teaching actions of Physical Education teachers. For this study, a questionnaire containing 26 statements was used. This questionnaire was developed based on the Likert scale, which is a psychometric scale widely used in qualitative research. This study is characterized as a descriptive research. This study used as a sample 6 teachers of Physical Education in the city of Mauriti-Ce. For the analysis of the answers obtained, a score was used in the teachers' actions. In this scoring model, the results that have an average higher than 3 show actions that make it possible and come close to Meaningful Learning. Already the averages below 3 show the use of methods focused on the Traditional Teaching methodology. The general average of the assertions, according to the data obtained from the answers, shows that the teachers perform in the classroom, practices that enable meaningful learning. The general average of 5 investigated teachers was higher than 3, reaching an average higher than 4 , in the statements regarding pedagogical actions that characterize methodologies aimed at meaningful learning. It can be observed that teachers know the importance of offering students the means and tools to provide meaningful learning in which the new content must be linked and connected to the student's knowledge about the proposed theme, so that he can learn. It is also important to emphasize that teachers need to review certain traditional pedagogical customs that do not favor a good quality of teaching, and in fact act and not just speak.
\end{abstract}

Keywords: Physical Education; Traditional Teaching; Meaningful Learning.

Topic: Práticas, Didática e Metodologias do Ensino

Reviewed anonymously in the process of blind peer.
Received: $22 / 10 / 2020$

Approved: 26/01/2021
Nathanael Rodrigues Magalhães

Centro Universitário Dr. Leão Sampaio, Brasil

http://lattes.cnpq.br/4043053350853553

nathanaelrodriguesluza@gmail.com

José de Caldas Simões Neto (iD

Centro Universitário Dr. Leão Sampaio, Brasil

http://lattes.cnpq.br/0470733825644726

http://orcid.org/0000-0003-1036-2315

ncaldas 22@hotmail.com

Pergentina Parentes Jardim Catunda (iD

Centro Universitário Dr. Leão Sampaio, Brasil

http://lattes.cnpq.br/6690006426950416

http://orcid.org/0000-0002-5631-897X

pergentina@leaosampaio.edu.br
Renan Costa Vanali (iD

Centro Universitário Dr. Leão Sampaio, Brasil

http://lattes.cnpq.br/0464534899158947

http://orcid.org/0000-0002-4193-3363

renan@leaosampaio.edu.br
Referencing this:

MAGALHAES, N. R.; SIMÕES NETO, J. C.; CATUNDA, P. P. J.; VANALI, R. C.. Investigações das ações pedagógicas dos professores de educação física: método tradicional $x$ aprendizagem significativa. Educationis, v.9, n.1, p.58-70, 2021. DOI: http://doi.org/10.6008/CBPC23183047.2021.001.0008

DOI: 10.6008/CBPC2318-3047.2021.001.0008 


\section{INTRODUÇÃO}

A Educação Física escolar busca no contexto atual de sua utilização, através da cultura corporal do movimento, formar seres com hábitos saudáveis, capazes de atuar em sociedade, de forma crítica, tornandose objetos transformadores de uma sociedade, cidadãos que tenham o conhecimento do seu verdadeiro papel no mundo. Porém tal papel não pode ser adquirido, recebendo uma educação que provenha do método tradicional de ensino, que não prepara o indivíduo de uma maneira que consiga aplicar o conhecimento adquirido em sala em suas futuras atuações (ESCOLA et al., 2019).

Esta realidade origina-se do ideal e o real mostra um ensino que tem proporcionado uma aprendizagem em que o discente venha a colocar em prática aquele conhecimento que obteve na escola. Esse método de ensino baseia-se no repasse de informações por parte dos professores, para alunos que se tornam meros espectadores, partindo de uma visão equivocada, em seres receptores de tal conhecimento, não serão capazes de participar de uma forma transformadora no momento vivenciado. Torna-se assim o professor como sendo o centro e principal agente dentro da sala de sala, sendo que tal posto deve ser ocupado pelo estudante (MORGADO et al., 2016).

Isso tem demonstrado ao longo da história, que a forma com que se vem pensando o modelo de sociedade, molda o comportamento da escola, e está por sua vez, reproduz este pensamento, na prática docente exercida dentro do ambiente escolar. Propondo um modelo de ensino tradicional, que não dá o suporte educacional necessário ao colegial, para que estes venham a se tornar futuras pessoas críticas, capazes de mudar as suas realidades (ARAÚJO, 2019).

Para que a sociedade não venha a ser apenas um lugar de reprodução de conhecimentos, mais sim um lugar em que o homem seja um agente transformador, um novo modelo de ensino toma o campo dos debates, a aprendizagem significativa, que já existe há muitos anos, e que com o crescente debate sobre a importância de mudar o contexto do processo de ensino e aprendizagem no ambiente escolar, atrelado as novas ferramentas existentes, principalmente aquelas que buscam o processo de desenvolvimento psicossocial do educando (ARAÚJO, 2019). A aprendizagem significativa tem como autor principal David Ausubel, essencialmente mais ligado à área dos estudos que envolvem a cognição, tem a preocupação inerente ao processo de compreensão, transformação e uso da informação transformação (MOREIRA, 2003).

Neste pensamento, considera-se que o aprendente é mentalmente capaz de receber, organizar e usar a informação adquirida para benefício próprio. Pesquisas mostram que o ensino superior caminha na direção da implantação de metodologias que estimula o aprendiz a ser ativo em seu processo de aprendizagem e tirem o professor do centro do processo do ensino tradicional, passando a exercer o papel de facilitador e não de transmissor de conhecimentos (MASSETO, 2012).

Atualmente vive-se um contexto, em que receber as informações provindas da escola e guardá-la na mente, a fim de apenas utilizá-la para sua sobrevivência, significa ir desarmado para uma guerra, em que a probabilidade de vitória, se encontra dentro dos mínimos níveis de possibilidades de acontecer. Vendramin et al. (2020) destacam que a aprendizagem significativa vem "sendo utilizada como ferramenta pedagógica 
que molda o acadêmico e o adapta as demandas que a existência atual exige, desenvolvendo um ser crítico, o tornando capaz de evoluir com seu conhecimento". A teoria da Aprendizagem Significativa de Ausubel, segundo Moreira et al. (2006) "preocupasse e encontra-se focado na capacidade de compreensão, no armazenamento e uso da informação recebida, para o bem próprio e dos que vivem a sua volta".

Espera-se que a Educação Física, no que se refere ao processo de ensino e aprendizagem no ambiente escolar, como uma ferramenta capaz, de através da cultura corporal do movimento, trabalhar conteúdos, usando de ferramentas metodológicas ativas, no intuito de formar fisicamente, psicologicamente e emocionalmente, indivíduos portadores de capacidades individuais, que tornem o lecionando um ser capaz de enxergar-se como uma pessoa totalmente capaz de modificar a sua realidade, através do pensamento crítico, quando o mesmo entender que algo está acontecendo de uma forma que pode ser melhorada (VENDRAMIN et al., 2020).

Assim através de muitos debates acerca da necessidade de mudar o rumo que a educação de nosso país tem trilhado, em que os crescentes debates concernentes a necessidade de mudar o contexto em que o ensino se encontra, tomando-se como certeza o fato de que a sala de aula não pode ser apenas um lugar em que a sua função é apenas acomodar o estudante, que são obrigados a assumir o mero lugar de ouvintes. "Mudanças que vêm ocorrendo no cenário social mundial nas últimas décadas, atribuídas aos avanços científicos e tecnológicos, têm desencadeado transformações em todas as áreas do conhecimento" (SILVA et al., 2014).

Portanto, é preciso que este modelo de educação tradicional seja aos poucos superado, para que o escolar possa assumir o seu verdadeiro papel dentro da sala de aula, usufruindo de um ensino pautado na inovação e no seu protagonismo no contexto escolar, vivenciando todas as possibilidades pedagógicas e inovadoras que o professor deve oferecer, no intuito de formá-lo cada vez mais crítico e atuante nos problemas de sua sociedade. Segundo Santana (2019) "Inovar em um contexto de aprendizagem evidencia a prática periférica do professor como um colaborador que abre espaço e permite as investidas do personagem principal, o aluno". Sendo o objetivo geral deste artigo, identificar as ações pedagógicas de ensino dos professores de Educação Física.

\section{METODOLOGIA}

Este estudo se caracteriza como uma pesquisa descritiva, de campo e de cunho quantitativa. As pesquisas descritivas objetivam identificar correlações entre variáveis e focam-se não somente na descoberta, mais também, análises dos fatos, descrevendo-os, classificando-os e identificando-os (FERNANDES et al., 2018). A utilização da quantificação é um aspecto encontrado em pesquisas notoriamente quantitativas (RICHARDSON, 1989). Já mensurações baseadas em comportamentos é característica de estudos qualitativos.

Este estudo utilizou como amostra 6 professores da disciplina de Educação Física da cidade de Mauriti-Ce. Selecionados pelos critérios de inclusão: a) professores da disciplina de Educação Física; b) com suas práticas pedagógicas voltadas para sua atuação na educação básica; c) professores da rede pública do 
município de Mauriti/Ce. Como critérios de exclusão: a) professores aposentados; b) professores que não estejam em atividade de docência e c) professores com formação em outra área, mesmo que ministrem aulas de educação física na educação básica.

Para a obtenção dos dados, foi aplicado o questionário contendo 26 afirmações, e tem seu embasamento inspirado na escala Likert, que é uma escala psicométrica muito utilizada em pesquisas de cunho quantitativo (BAKER, 1995). As perguntas não foram dispostas em sequência lógica, ou seja, elas se intercalam no decorrer do questionário, em que os participantes responderam simultaneamente perguntas relacionadas e voltadas para a Aprendizagem Significativa e Ensino Tradicional. Em cada pergunta proposta, os professores se posicionaram na escala, que traz a frequência das ações em suas aulas. 0 número 1 corresponde às ações que sempre são utilizadas em sala de aula, o 2 às que são frequentemente, o 3 às que são usadas às vezes, o 4 às que raramente são utilizadas e o 5 às que nunca são usadas (DARROZ et al., 2015).

O questionário é dividido em dois grupos distintos, a primeira parte é composta pelas assertivas 02 , $07,08,09,11,13,15,17,18,20,21,23$ e 24 , e buscou verificar as práticas pedagógicas voltadas para um ensino baseado na Aprendizagem Significativa. Já o segundo é atribuído as assertivas 01, 03, 04, 05, 06, 10, 12, 14, 16, 19, 22, 25 e 26, em que dizem respeito à metodologia de Ensino Tradicional, em que busca avaliar por parte dos professores métodos de transmitir a informação, em que o professor aparece como detentor do conhecimento (DARROZ et al., 2015).

Cada participante respondeu individualmente o questionário, visto que a avaliação dos dados foi feita de forma online e individual, para obtenção do resultado geral. O projeto foi submetido ao Comitê de Ética em Pesquisa do Centro Universitário Dr. Leão Sampaio (UNILEÃO) para apreciação, com aprovação do parecer № 4.385.607. Todos os participantes foram informados dos procedimentos a adotados na pesquisa e foram orientados a assinar um Termo de Consentimento Livre e Esclarecido (TCLE) em acordo a resolução 466/12 do Conselho Nacional de Saúde.

Para a análise dos dados foi empregada uma pontuação para cada ação dos professores. Neste modelo de pontuação, os resultados que tenham média superior a 3 mostram ações que possibilitam e se aproximam da Aprendizagem Significativa. Já as médias abaixo de 3 evidenciam a utilização de métodos voltados para a metodologia do Ensino Tradicional. Com estes valores foi feita a média de cada professor, como mostra a tabela abaixo (DARROZ et al., 2015).

Quadro 1: Pontuação dos valores na tabela.

\begin{tabular}{|l|l|}
\hline Valor assinalado & Ponto adicionado \\
\hline Aprendizagem Significativa & 5 \\
\hline 1.Sempre realizo & 4 \\
\hline 2.Realizo frequentemente & 3 \\
\hline 3.Ás vezes & 2 \\
\hline 4.Realizo raramente & 1 \\
\hline 5.nunca & \multicolumn{2}{|l}{} \\
\hline Ensino Tradicional & 5 \\
\hline 1.Sempre realizo & 4 \\
\hline 2.Realizo frequentemente & 3 \\
\hline 3.Ás vezes & 2 \\
\hline 4.Realizo raramente & 1 \\
\hline 5.Nunca & \\
\hline
\end{tabular}

Fonte: DARROZ et al. (2015). 
Como sendo um estudo de estatística descritiva por meio de média, à medida que os professores responderam os questionários, foi feito o recolhimento online, para serem feitas quantitativamente as coletas, análises e interpretações, sem qualquer interação com as respostas.

\section{RESULTADOS E DISCUSSÃO}

Através do valor assinalado foi possível construir a média dos professores participantes desta pesquisa e a análise de cada questão vem apresentada na Tabela 01, para uma avaliação para detalhada por assertiva. Os escores que se encontram superiores a 3 mostram que as ações tomadas pelos professores, fazem com que uma aprendizagem significativa seja proporcionada através dos conteúdos propostos. Com esse olhar mais detalhado por assertiva possibilita observar ações pontuais em que os professores têm práticas pedagógicas voltadas para aprendizagem significativa ou se suas ações são tomadas através do ensino tradicional.

Desta maneira e com base na verificação e análise da tabela 1, verifica-se que nas respostas das assertivas A12, A16 e A22, todos os professores entrevistados têm uma pontuação menor que 3, ou seja, demonstram ser professores mais técnicos, que utilizam de ferramentas pedagógicas que remetem a um ensino tradicional.

Ao serem questionados nas assertivas, A12 se constroem as suas provas com questões semelhantes aos exercícios das aulas, A16 se usam listas de exercícios de fixação dos conteúdos estudados e A22 se iniciam a aula com a apresentação de algum conteúdo para posteriormente apresentar-Ihes questões relacionadas ao que foi explicado, todos os professores tiveram uma média menor que 3, apresentando ações características do ensino tradicional.

Tabela 1: Análise das assertivas sobre o ensino das aulas de Educação Física.

\begin{tabular}{|c|c|c|c|c|c|c|c|c|c|}
\hline \multicolumn{5}{|c|}{ Ensino Tradicional } & \multicolumn{5}{|c|}{ Aprendizagem Significativa } \\
\hline \multirow{2}{*}{ Afirmativa } & \multicolumn{3}{|c|}{$N=(06)$} & \multirow{2}{*}{ Média } & \multirow{2}{*}{ Afirmativa } & \multicolumn{3}{|c|}{$N=(06)$} & \multirow{2}{*}{ Média } \\
\hline & $<3$ & 3 & 3> & & & $<3$ & 3 & 3> & \\
\hline A1 & 4 & 0 & 2 & 2,2 & $\mathrm{~A} 2$ & 0 & 0 & 6 & 5,0 \\
\hline A3 & 3 & 2 & 1 & 2,5 & A7 & 1 & 2 & 3 & 3,6 \\
\hline A4 & 3 & 1 & 2 & 2,8 & A8 & 1 & 0 & 5 & 4,1 \\
\hline A5 & 5 & 1 & 0 & 1,3 & A9 & 0 & 4 & 2 & 3,3 \\
\hline A6 & 3 & 2 & 1 & 2,8 & A11 & 1 & 0 & 5 & 4,1 \\
\hline A10 & 4 & 2 & 0 & 1,8 & A13 & 1 & 0 & 5 & 4,1 \\
\hline A12 & 6 & 0 & 0 & 1,2 & A15 & 1 & 1 & 4 & 3,8 \\
\hline A14 & 4 & 1 & 1 & 2,3 & A17 & 0 & 1 & 5 & 4,1 \\
\hline A16 & 6 & 0 & 0 & 1,3 & A18 & 1 & 1 & 4 & 4,0 \\
\hline A19 & 0 & 4 & 2 & 3,5 & A20 & 0 & 3 & 3 & 3,6 \\
\hline $\mathrm{A} 22$ & 6 & 0 & 0 & 1,2 & $\mathrm{~A} 21$ & 0 & 0 & 6 & 4,6 \\
\hline $\mathrm{A} 25$ & 5 & 0 & 1 & 2,3 & A23 & 1 & 0 & 4 & 4,0 \\
\hline $\mathrm{A} 26$ & 3 & 1 & 2 & 2,8 & A24 & 0 & 1 & 5 & 4,3 \\
\hline
\end{tabular}

Pelas respostas dos professores, percebe-se a utilização de metodologias voltadas a um ensino tradicional, em que não são oferecidos meios para a existência de uma formação completa dos alunos. Pois neste modelo o ensino que o educando recebe é baseado em repetições de conteúdo, exigindo dos escolares apenas ser um bom memorizador de informações (SANTANA, 2019).

Quando perguntados se iniciam as suas aulas expondo teoricamente os conteúdos a serem estudados na assertiva A5, a média de 5 professores foram inferiores a 3, e 1 professor com média igual a 3, 
ocorrendo aqui o primeiro contraste acerca de como os professores introduzem os conteúdos, pois na assertiva A2 quando questionados se iniciam suas aulas pela explanação do que o aluno já sabe, todos os docentes tiveram média superior a 3, ou seja, ao mesmo tempo que afirmar dar início aos conteúdos a partir do conhecimento que o aluno já tem, os professores afirmam que a nova temática é feita sob a apresentação teórica do novo conteúdo. Sendo assim, percebe-se que os professores sabem da importância de apresentar os organizadores prévios aos alunos, mas preferem seguir práticas voltadas ao ensino tradicional.

A aprendizagem proposta por Ausubel ocorre quando a informação apresentada ao aluno interage com a informação que o aluno já tem conhecimento, assim o aluno aprenderá desta forma, de uma maneira não arbitrária e não literal. "A aprendizagem preconizada por Ausubel ocorrerá quando o novo conteúdo interagir com conceitos subsunçores relevantes presentes na estrutura cognitiva do estudante, de forma não arbitrária e não literal" (DARROZ et al., 2015). Deste modo pode-se entender a importância de apresentar aos aprendizes conteúdo baseados naquilo que eles já sabem.

$\mathrm{Na}$ afirmativa $\mathrm{A} 7$ todos os professores obtiveram uma média superior a 3 , em que afirmaram proporcionar situações em que o estudante confronte o seu conhecimento com aquilo que já sabe. Vendramin et al. (2020) afirmam que Ausubel desenvolveu a teoria da Aprendizagem Significativa buscando entender como acontece o processo de aprendizagem, afirmando que a aprendizagem do aprendiz acontecerá a partir do seu conhecimento acerca de determinado tema, aliado aos materiais potencialmente significativos e a sua disposição em aprender de forma significativa.

A assertiva A8 é referida aos conteúdos apresentados aos alunos, com potencial significativo, ou seja, de oferecer ao acadêmico uma aula pautada naquilo que é importante para ele. Cabendo ressaltar conforme afirmam Vendramin et al. (2020), é muito importante nesse processo de aprendizagem do aluno, o professor utilizar ferramentas pedagógicas significativas. Neste entendimento é dada uma nova dinâmica as suas aulas com a participação efetiva do aluno nos debates, fazendo com que cada encontro seja atrativo para o aprendiz.

É importante observar bem os resultados das assertivas A1 e A15, pois em ambas os docentes são questionados acerca da utilização de vídeos, livros, textos e fragmentos científicos na apresentação dos conteúdos, de forma que na assertiva A1, 4 professores tiveram médias menores que 3, mostrando serem profissionais que iniciam suas temáticas de uma forma mais tradicional, e 2 professores tiveram médias superiores a 3, enquanto na afirmativa $A 15,4$ professores entrevistados obtiveram uma média superior a 3 , ficando 1 professor com média igual a 3 e 1 professor com média menor que 3, assim, a maioria busca apresentar novos meios de modificar a rotina tradicional das aulas, proporcionando uma aprendizagem significativa.

A utilização de materiais que não se restrinjam apenas ao uso do livro didático é uma prática que pode modificar o interesse do aluno em aprender o conteúdo que lhe é apresentado, e para que o aluno aprenda de uma forma significativa são necessários três aspectos importantes que devem ser levadas em consideração pelo professor no processo de ensino (DARROZ et al., 2015).

A aprendizagem significativa ocorrerá sob três condições importantes: conhecimento prévio 
relevante, material significativo, e ainda, o estudante deve optar por aprender de forma significativa. A primeira requer que ele tenha um conhecimento âncora relevante, caso o acadêmico não tenha conhecimento prévio do novo conceito, a aprendizagem significativa não pode ocorrer. Na segunda condição, aparece a figura do professor, que deve disponibilizar materiais significativos para o acadêmico. A terceira condição diz respeito ao interesse do estudante de aprender de forma significativa, onde este aprendizado deve ser estimulado pelo professor, para que o aluno se mostre interessado (AUSUBEL et al., 1968; NOVAK, 1998; VENDRAMIN et al., 2020).

Já na afirmativa A13 os professores parecem demonstrar saber da importância em exercer um papel de mediador durante as aulas, dando aos acadêmicos, autonomia e liberdade no processo de ensino e aprendizagem, proporcionando que estes sejam sujeitos ativos nas discussões das aulas. Nesta assertiva 5 professores atingiram uma média maior que 3 e 1 com média inferior a 3.

Porém na assertiva A14 nota-se uma grande diferença em relação ao professor mediador, 4 professores investigados tiveram média inferior a 3, 1 professor com média igual a 3 e 1 professor com média maior que 3, em que através de suas respostas assumem que durante a explanação das temáticas, o aluno deve apenas prestar atenção a fala do professor. Esse resultado nos dá a possibilidade de entender que os professores se sentem atores principais durante as aulas, não permitindo ao aluno incluir-se efetivamente na aula, dando a esta atitude aspectos de um ensino tradicional.

Este modelo é facilmente detectado quando se observa salas de aula em que as cadeiras se encontram colocadas frente ao quadro, e os professores são os detentores dos conhecimentos, transmitindo as informações aos acadêmicos, que observam o professor falar por vários minutos, ou seja, é um recorte de um modelo de ensino e aprendizagem, vivenciado no passado e no presente (MENDONÇA et al., 2019). Desta forma percebe-se que a educação que o estudante tem recebido em sala de aula, não está lhe proporcionando um pleno desenvolvimento de suas capacidades cognoscitivas, importante para a sua formação.

Na afirmativa de número $A 10$ os professores foram questionados se realizam suas atividades práticas com roteiros preestabelecido, assim, 4 professores tiveram média menor que 3 e 2 professores tiveram média igual a 3, em que o objetivo desta assertiva é saber com que frequência o método tradicional é utilizado em atividades práticas, e se o aluno seguirá um roteiro pré-estabelecido, com pouco espaço de participação nas aulas, restrito ao papel de espectador, longe de uma realidade que o proporcione aprender de uma forma significativa, ao contrário, fazendo com que o aluno não enxergue-se como agente fundamental no futuro de sua sociedade.

Apesar de mostrarem adotar metodologias tradicionais nas atividades práticas e diante do que foi exposto no gráfico, vê-se outro contraste, pois diante disso, todos os professores tiveram médias superiores a 3 na alternativa A21, afirmando que oferecem aos estudantes durante os momentos das aulas um determinado espaço para que possam posicionar-se e expressar suas acentuações acerca do assunto abordado, evidenciando uma atitude voltada para aplicação da aprendizagem significativa.

A assertiva A9 é voltada para investigar se os professores usam mapas conceituais como 
instrumento didático nas aulas de Educação Física, constatando o fato que a maioria dos professores não utiliza os mapas conceituais para organizar os conteúdos de suas aulas, pois 2 professores tiveram uma média maior que 3, e 4 professores com médias iguais a 3, constatando a pouca utilização desta ferramenta metodológica. A média da assertiva A9 mostra que os professores na maioria das vezes não se preocupam em organizar os conteúdos para ministrá-los de uma forma organizada, apresentando as temáticas aos alunos, sem apresentá-las de uma forma organizada, dificultando o entendimento do aluno acerca do conhecimento apresentado, fato que poderia ser evitado com a utilização dos mapas conceituais.

Os mapas conceituais promovem integração, conciliação e um bom entendimento do novo assunto que é apresentado ao estudante e ainda s mapas são diagramas que podem indicar relação entre as palavras usadas para representar os conceitos (DARROZ et al., 2015).

A assertiva A17 se refere ao uso da memória no processo de ensino. "Essa é uma atividade que possibilita ao aluno retomar, de forma reflexiva, os conteúdos trabalhados, além de permitir ao professor analisar aquilo que o sujeito julgou mais importante e assimilou melhor" (DARROZ et al., 2015). Neste item 5 professores obtiveram média superior a 3, e 1 professor com média igual a 3 . Sendo assim, até o presente foram analisados e discutidos os resultados pontuando as médias de cada assertiva, a seguir será discutido os resultados gerais de todos os professores, como mostra a imagem 1.

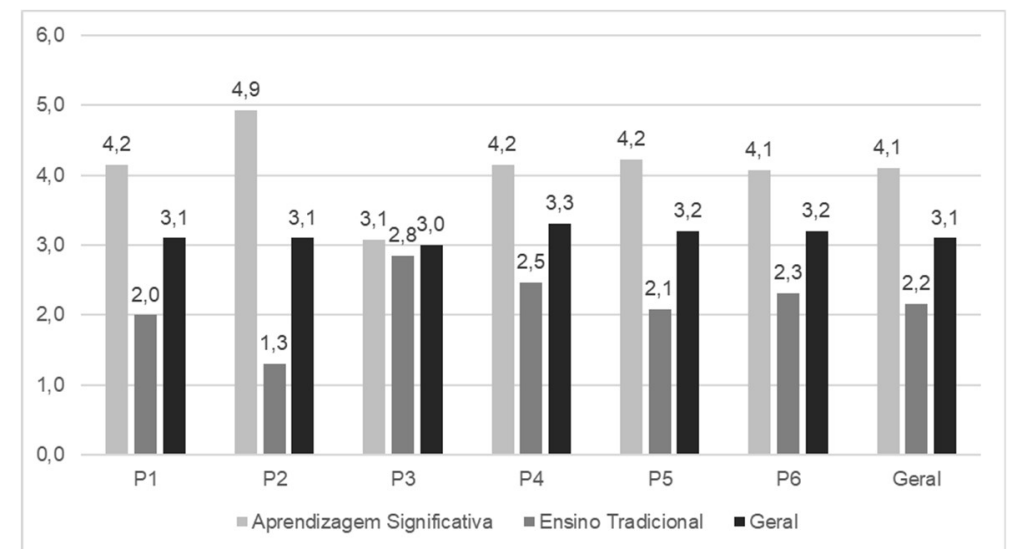

Imagem 1: Média geral dos professores sobre o ensino das aulas de Educação Física.

A média geral dos professores investigados foi superior a 3, nas assertivas referente as ações pedagógicas que caracterizam metodologias voltadas para a aprendizagem significativa, mostra-se que conforme assinalado neste grupo de alternativas, a maioria dos professores sabem da importância em utilizar métodos e práticas que proporcionem aos alunos uma aprendizagem significativa. Apenas o professor 3 atingiu uma média próxima de 3, que apesar de obter uma média 3,1, mostra que seus métodos se distanciam um pouco dos demais professores. Já as médias gerais no tocante as alternativas que buscam investigar e evidenciar metodologias e hábitos pedagógicos voltados ao ensino tradicional, alcançaram média geral inferior a 3, assim, as aulas dos professores acontecem e são ministradas dentro ações que possibilitam uma aprendizagem significativa.

O resultado da média geral dos professores é um reflexo de suas ações dentro da sala de aula, que por sua vez são atitudes importantes no processo de ensino dos conteúdos da Educação Física com ênfase 
no modelo da aprendizagem significativa. Desta forma a aprendizagem significativa é um modelo de ensino que pode e deve ser utilizada pelos professores de Educação Física na organização e aplicações dos conteúdos em aula, atentando sempre para a importância de considerar o conhecimento que o estudante já tem sobre determinado assunto. A importância do significado dos novos conhecimentos depende diretamente da existência dos conhecimentos prévios especificamente relevantes para o sujeito, bem como da interação entre eles (SILVA, 2020).

Por ser uma teoria que trata o aluno como ser capaz de aprender a partir das interações e correlações entre informações e que modifica a estrutura das aulas no contexto escolar, dando ênfase principal a figura do estudante, tirando de cena um processo pautado em um modelo tradicional de ensino, a aprendizagem significativa é um tema pesquisado por algumas disciplinas, como: Matemática, Química, Física e outras áreas do conhecimento que buscam em seu embasamento melhorar o processo de ensino e aprendizagem nas aulas.

Lima (2019) em seu estudo denominado “A importância da sequência didática para a aprendizagem significativa da matemática" buscou analisar como poderia ocorrer uma aprendizagem significativa através da sequência didática como sendo mecanismo para desenvolver a educação matemática no ensino fundamental, correlacionando conteúdo x cotidiano do aluno. Afirma que "na prática isso não ocorre e os alunos resolvem problemas sem se importar em entender seu real significado". Neste sentido o aluno domina a teoria, mais nenhum sentido lhe é atribuído para que o aluno sinta o desejo de aprender de forma significativa.

Outrossim, nota-se a importância de teorias como a aprendizagem significativa no campo pedagógico, com atributos capazes de modificar a dinâmica das aulas, que muitas vezes se tornam repetitivas e monótonas, fazendo com que o aluno não sinta o desejo de participar ativamente daquele momento de aprendizagem, sendo este um assunto muito discutido e visto na realidade das aulas de Educação Física.

A Educação Física escolar vem ao longo de muitos anos sendo considerada como uma disciplina não necessária ao currículo escolar por alunos, professores de outras disciplinas e algumas autoridades educacionais do Brasil. Segundo Lee (2002), a disciplina sofre com questionamentos no decorrer dos anos, tendo seu prestígio abalado e no que diz respeito a oferecer uma aprendizagem significativa, tem falhado bastante, porém esta realidade precisa ser modificada, através do engajamento dos professores e demais gestores escolares no intuito de buscar novas metodologias e debates sobre práticas que fomentem a importância da Educação Física escolar.

Nesta perspectiva, para que o aluno consiga aprender os conteúdos da disciplina de Educação Física, é necessário que o professor procure fazer uma conexão entre o conhecimento que o aluno tem sobre alguma temática da área, ao novo conhecimento apresentado. Conforme afirmam Vendramin et al. (2020) uma forma que pode fazer com que exista uma aprendizagem significativa é relacionar a informação a estrutura cognitiva do aluno, para que possa interagir com o conteúdo de uma forma não-arbitrária ${ }^{1}$ e não- 
literal ${ }^{2}$.

O modelo de aprendizagem significativa pode ainda beneficiar um melhor aproveitamento do tempo de aula, bem como a organização dos conteúdos, visto que a Educação Física é uma disciplina que dentro do ambiente escolar não dispõe de uma quantidade de horas/aulas suficientes que permita ao professor apresentar aos discentes uma maior variedade de conteúdos de uma forma mais organizada, e para que o professor possa organizar melhor suas aulas, ele pode fazer uso dos mapas conceituais. Trata-se de representações esquemáticas de conceitos ligados entre si por unidades semânticas denominadas proposições (MACHADO et al., 2019).

Devido experiências negativas que a maioria dos alunos traz das aulas de Educação Física, muitos deles não se sentem atraídos para as aulas, e para que tal atração possa acontecer e o aluno obtenha uma aprendizagem significativa, o professor pode fazer uso de alguns princípios da teoria da aprendizagem significativa, como apresentar materiais significativos e conhecimentos relevantes aos aprendizes, fazendo assim com que ele sinta o desejo em aprender de forma significativa.

Ainda é importante ressaltar que a Educação Física é uma disciplina de inquestionável importância no currículo escolar, pois aborda temáticas relacionadas à saúde e a qualidade de vida, como também a formação integral do aluno em seus aspectos sociais e psicomotores, através da cultura corporal do movimento. Por tudo apresentado e discutido até aqui, o modelo da aprendizagem significativa é uma ferramenta metodológica de grande importância para o professor de Educação Física, bem como para os demais profissionais da educação, para uma melhor organização dos conteúdos, aproveitamento do tempo de aula e melhor uma aprendizagem dos conteúdos aos estudantes.

\section{CONCLUSÕES}

Práticas pedagógicas que remetam a uma metodologia de ensino tradicional vêm sendo amplamente revistas pela comunidade acadêmica e científica, pois este modelo já não é capaz de oferecer uma formação integral ao aluno, de forma que se preparem para vencer os desafios de sociedade a qual fazem parte. Pode-se observar que os professores sabem da importância em oferecer aos estudantes, meios e ferramentas que proporcione uma aprendizagem significativa, em que os novos conteúdos devem estar atrelados e conectados ao conhecimento do aluno sobre a temática proposta, para que possa aprender. Por isso é importante entender que os alunos trazem consigo uma vasta gama de conhecimentos que devem ser levados em consideração.

Ainda é importante ressaltar que os professores precisam rever certos costumes pedagógicos tradicionais que não favorecem a uma boa qualidade de ensino, e de fato agir e não somente falar, pois através da análise dos dados que os professores tem consciência da necessidade do uso de novas metodologias e práticas que somem positivamente ao processo de formação do aluno, como o modelo da aprendizagem significativa, porém reproduzem através de suas atitudes dentro do contexto escolar, a 
manutenção de uma educação pautada ainda sob um viés tradicional.

Desta forma esta investigação buscou da melhor maneira apresentar os resultados através das análises pautadas nas discussões que foram colocadas, buscando apresentar aos professores de Educação Física e demais disciplinas que a aprendizagem significativa é uma teoria a ser utilizada pelos professores na sala de aula, que pode trazer um grande crescimento no que diz respeito à formação integral dos alunos.

Por conta da pandemia global do coronavírus, houve uma diminuição da amostra deste estudo, pelo fato de que o questionário folheado não pode ser aplicado neste momento, por conta do isolamento social, modificado para uma forma eletrônica, e devido dificuldades de acesso, não chegou ao número esperado de sujeitos. A inexistência de incentivos e recursos financeiros provindos de algum órgão educacional ou da própria instituição foi um fator que limitou que um maior número de professores participasse deste estudo, ou seja, professores de outras cidades.

Através da proposta deste estudo surgem alguns questionamentos que podem servir de influenciadores para novas investigações na área pedagógica, como por exemplo: Os professores realizam em sala aquilo que dizem quando questionados acerca de suas práticas? Os alunos querem aprender de uma forma significativa? Qual sociedade será construída em nosso país, caso a metodologia do ensino tradicional seja mantida e reproduzida pelos professores na escola? A escola está apta a oferecer um ensino baseados em novas metodologias? A escola oferece meios para que o professor possa desenvolver novas formas de ensinar?

Por fim sabe-se que é preciso e necessário que ferramentas metodológicas como a aprendizagem significativa sejam implantadas as metodologias tidas como essenciais à propagação de um ensino pautado em uma completa formação do aluno, e que o professor de Educação Física pode dar um novo rumo a esta disciplina em nosso país, dando ênfase principal no processo de ensino e aprendizagem ao aluno. Afinal podese acompanhar um processo pelo qual Educação Física quase foi excluída do currículo escolar, pois diante de alguns olhares de algumas autoridades educacionais, está disciplina não tem utilidade para a formação dos alunos.

\section{REFERÊNCIAS}

ARAÚJO, M. F.. Pedagogia tradicional: aspectos presentes na prática docente no contexto atual. Monografia (Licenciatura em Pedagogia) - Universidade Federal do Rio Grande do Norte, Caicó, 2019.

AUSUBEL, D. P.; NOVAK, J.D.; HANESIAN, H.. Pisicologia educacional. New York: Holt, Rinehartand Winston, 1968.

BAKER, M.. Corporaem estudos da tradução: uma visão geral e algumas sugestões para pesquisas futuras. Alvo Revista Internacional de Estudos de Tradução, Londres, v.7, n.2, p.223-243, 1995.

DARROZ, L. M. ROSA, C. W. GHUIGGI, C. M.. Método tradicional $x$ Aprendizagem significativa: Investigação na ação dos professores de Física. Meaningful Learning Review, Passo Fundo, v.5, n.1, p.70-85, 2015.
ESCOLA, A.; FERREIRA, E.. (Re)agir sobre as fragilidades do exercício da cidadania na escola. Porto: Lisboa, 2019.

FERNANDES, A. M.; BRUCHÊSZ, A.; D'ÁVILA, A. A. F.; CASTILHOS, N. C.; OLEA, P. M.. Metodologia de pesquisa de dissertações sobre inovação: Análise bibliométrica. Desafio Online, Campo Grande, v.6, n.6, p.142-159, 2018.

LEE, A. M.. Promoting quality school physical education: exploring the root of the problem. Research Quarlety for Exercise and Sport, v.73, n.2, p.118-124, 2002.

LIMA, J. M. P.. A importância da sequência didática para a aprendizagem significativa da matemática. Revista Artigos, v.2, p.1-8, 2019.

MACHADO, C. T.; CARVALHO, A. A.. Os efeitos dos mapas conceituais na aprendizagem dos estudantes universitários. 
Educação Temática Digital, Campinas, v.21, n.1, p.259-277, 2019.

MASSETO, M. T.. Competência pedagógica do professor universitário. São Paulo: Summus, 2012

MENDONÇA, R. R.; BARBOSA, A. J. G.. Habilidades de resolução de problemas e métodos de ensino: o método montessori e o ensino tradicional em questão. Psicologia da Educação, São Paulo, e.49, p.3-12, 2019.

MOREIRA, M. A.. Linguagens e aprendizagem significativa. Porto Alegre: Instituto de Física da UFRGS, 2003.

MOREIRA, M. A.; MASINI, E. F. S.. Aprendizagem significativa: a teoria de David Ausubel. São Paulo: Centauro, 2006.

MORGADO, S.; LEITE, L.; DOURADO, L. FERNANDES, C.; FILVA, E.. Ensino orientado para a aprendizagem baseada na resolução de problemas e ensino tradicional: um estudo centrado em "transformação de matéria e de energia". Ens. Pesqui. Educ. Ciênc., Belo Horizonte, v.18, n.2, p.7398, 2016.
NOVAK, J. D.. Learning, creating and using knowledge:

concept maps as facilitative tools in schools and corporations. New York and London: Routledge, 1998.

RICHARDSON, R. J.. Pesquisa Social: Métodos e técnicas. São Paulo: Atlas S.A., 1989.

SANTANA, T. P.. Prática pedagógica tradicional e inovadora. Revista Espaço Acadêmico, v.19, n.216, p.55-62, 2019.

SILVA, J. B.. A teoria da aprendizagem significativa de David Ausubel: Uma análise das condições necessária. Research, Socyte and Development, v.9, n.4, p.1-13, 2020.

SILVA, S. C. R.; SCHIRLO, A. C.. Teoria da aprendizagem significativa de Ausubel: Reflexões para o ensino de Física ante a nova realidade social. Imagem da Educação, Ponta Grossa, v.4, n.1, p.36-42, 2014.

VENDRAMIN, E. O.; ARAUJO, A. M. P.. A teoria da aprendizagem significativa e a estratégia de ensino método do caso: um estudo no ensino superior de contabilidade introdutória. Revista Gestão Universitária na América Latina - GUAL, Florianópolis, p.157-179, 2020. 